\title{
SORPTION OF SATURATED AND UNSATURATED HYDROCARBONS ON SELECTED COAL SAMPLE FROM THE PNIÓWEK MINE
}

\section{Pawel BARAN ${ }^{1}$, Janusz CYGANKIEWICZ ${ }^{2}$, Andrzej KRZYŻANOWSKI ${ }^{1}$ \& Katarzyna ZARĘBSKA ${ }^{1}$}

\author{
${ }^{1}$ AGH University of Science and Technology, Faculty of Energy and Fuels; \\ al. Mickiewicza 30, 30-059 Krakow, Poland; \\ e-mail: zarebska@uci.agh.edu.pl \\ ${ }^{2}$ Central Mining Institute, Department of Mining Aerology; \\ Plac Gwarków 1, 40-166 Katowice, Poland; \\ e-mail:bdxjc@gig.katowice.pl
}

\begin{abstract}
Type, amount and composition of gases which form in rocks and coals during a metamorphism process depend on a number of factors in particular genetic type of original matter, way and conditions of its gathering, temperature, pressure and geological time. Sorption tests were done by the volumetric method, with the use of adsorption micro-burettes. A major advantage of the measurement set-up is that the surplus amounts of adsorbate can be used in experiments, which is of particular importance when handling sorbents with heterogeneous structure, such as hard coals. Sorbates used in the test program were the vapours of hexane, hex-1-ene, heptane, hept-1-ene, octane and benzene. Measurement results seem to corroborate the hypothesis that sorption of polar substance vapours is chiefly a surface process. Polarity of hard coals, mostly associated with the presence of reactive oxygen groups (nitrogen and sulphuric groups), largely affects the sorption of polar substances and in a most characteristic manner controls the sorption of apolar ones. In the case of the latter, sorption is induced by the action of the dispersive interaction force between the coal surface and the sorbate's polar molecules. The pattern of sorption isotherms indicates that the presence of dual bond affects the sorbent-sorbate interactions and hence the sorption capacity of investigated coals.
\end{abstract}

Key words: sorption, coal, saturated and unsaturated hydrocarbons 


\section{INTRODUCTION}

Coal has a prominent rank among sedimentary rocks, due to its origins and transformations of organic matter throughout the coalification process, leading to formation of solid and gaseous substances both within the porous coalbeds and between the beds. That determines the distinctive properties of a majority of coals: they are able to act as specific gas collectors and mine gases can accumulate in the coal's porous structure (Walker et al. 1988). The amount of gas accumulated in the coalbed is dependent on its sorption capacity and the coalbed size. Under certain conditions, this mine gas can be released from the disturbed coalbed. The main components of the mine gas are: methane, nitrogen, carbon dioxide or their mixture though the presence of higher gaseous hydrocarbons $(\mathrm{C} 2-\mathrm{C} 8)$ is of major importance too, as their contents in some sections of coal-bearing formations may exceed even 10\% (Kotarba 2001). The presence of hydrocarbons can give rise to such phenomena as rock gas outbursts or methane explosions while the coalbed is being mined, and the mechanisms of their interactions with the coal bulk have not been fully explained yet (Sobczyk 2011). While exploring the potentials of a rock and gas outburst occurrence, the following parameters of coal are of particular importance: porosity, rock cohesion, the level of structural damage, maceral composition, moisture and sorption capacity with respect to gases contained in coalbeds (Clarkson \& Bustin 1999, Vuthaluru et al. 2003). Most studies reported in literature have focused on sorption and desorption of methane or carbon dioxide (Shi \& Durucan 2003, Chen et al. 2007, Prusty 2007, Labus et al. 2010). The current data base of experimental data collected under conditions similar to those prevailing in situ is still limited, which is mostly due to the fact that it takes a long time before the sorption equilibrium conditions can be established. There are few reports, however, concerning sorption and desorption of hydrocarbons on hard coals (Bradley \& Rand 1995, Huang et al. 2002, Mirasol et al. 2005, Krzyżanowski \& Żyła 2007, Orzechowska-Zięba \& Nodzeński 2008). That sorption equilibrium is hard to establish in hard coals, which is mostly due to their structural heterogeneity and non-rigidity of material (Nodzeński et al 2003). The heterogeneous structure of coal leads to some difficulties in identification and quantitative determination of involved chemical structures, which would explain the elemental composition of coal, both in qualitative and quantitative terms. Furthermore, when planning the future use of laboratory test data one should take into account the fact that in subsequent stages of the process different gases will be released and that they may additionally flow into a coalbed from different sources. From the standpoint of mining practice, a good insight into those processes is of primary importance as the test results can be utilised to determine the suitability of selected coal types to be used for storage or release of aliphatic hydrocarbons.

The coal structure is mostly apolar, though the presence of functional groups lends the specific level of polarity to the coal bulk (Youssef 1974). The coal surface contains numerous functional groups, such as oxygen groups, which act as regulators of hydrophilic properties of the coal surface (Żyła \& Kreiner 2006). It is a well-established view, therefore, that hard coal behaves as a dual system, exhibiting both hydrophobic and hydrophilic properties. This dual nature of the coal surface is of particular importance when investigating 
the sorption of vapours of apolar and polar substances. Polarity of hard coals, mostly associated with the presence of reactive oxygen groups (nitrogen and sulphuric groups), largely affects the sorption of polar substances and in a most characteristic manner controls the sorption of apolar ones. In the case of the latter, sorption is induced by the action of the dispersive interaction force between the coal surface and the sorbate's polar molecules.

\section{METHODS}

Sorption tests were done by the volumetric method, with the use of adsorption microburettes. A major advantage of the measurement set-up is that the surplus amounts of adsorbate can be used in experiments, which is of particular importance when handling sorbents with heterogeneous structure, such as hard coals. The measuring device is placed inside an air thermostat to maintain the constant temperature, with the accuracy $0.1^{\circ} \mathrm{C}$. Prior to the experiments, previously sorbed gas molecules and vapours of various chemical substances have to be removed from the coal surface and from the pores, so the coal samples were evacuated under vacuum, of the order of $10^{-3} \mathrm{~Pa}$ and subjected to the helium rinse to enhance the degassing efficiency. Helium atoms do not get adsorbed, but supply the required kinetic energy to molecules of absorbed vapours and gases, knocking them out from the sorbent's surface (Saha et al. 2007). In order to average the physicochemical properties of the sample and increase the kinetic measure studies were carried out at $303 \mathrm{~K}$, on the grain fraction 0.125-0.250 mm, using fluid micro-burettes equipment.

\section{STUDY AREA}

Sorbates used in the experiments included aliphatic hydrocarbons as sorbates: hexane, heptane and octane and, for comparison, two of hydrocarbons containing a dual bond: 1-hexen and 1-hepten as well as an aromatic hydrocarbon: benzene, containing delocalised electrons. The selection of sorbates was prompted by cognitive issues as well as practical aspects. Sorbates differ in terms of their structure, molecule size and physical properties, they are also present as components in gas mixtures, such as mine gas in coalbeds. Physico-chemical properties of sorbates used in the experiments are summarised in Table 1.

Table 1

Selected physico-chemical properties of sorbates

\begin{tabular}{|c|c|c|c|c|c|c|}
\hline \multirow{3}{*}{ Characteristic } & \multicolumn{3}{|c|}{ Saturated sorbates } & \multicolumn{2}{c|}{ Unsaturated sorbates } & $\begin{array}{c}\text { Aromatic } \\
\text { sorbates }\end{array}$ \\
\cline { 2 - 8 } & Hexane & Heptane & Octane & Hex-1-ene & Hept-1-ene & Benzene \\
\cline { 2 - 7 } & $\mathrm{C}_{6} \mathrm{H}_{14}$ & $\mathrm{C}_{7} \mathrm{H}_{16}$ & $\mathrm{C}_{8} \mathrm{H}_{18}$ & $\mathrm{C}_{6} \mathrm{H}_{12}$ & $\mathrm{C}_{7} \mathrm{H}_{14}$ & $\mathrm{C}_{6} \mathrm{H}_{6}$ \\
\hline Boiling temperature [K] & 341.83 & 371.57 & 398.84 & 336.63 & 366.77 & 353.30 \\
\hline Melting temperature [K] & 177.83 & 182.57 & 216.37 & 131.32 & 154.12 & 278.70 \\
\hline
\end{tabular}


Table 1 cont.

\begin{tabular}{|c|c|c|c|c|c|c|}
\hline \multirow{2}{*}{\begin{tabular}{c} 
Characteristic \\
\cline { 2 - 7 }
\end{tabular}} & \multicolumn{3}{|c|}{ Saturated sorbates } & Unsaturated sorbates & $\begin{array}{c}\text { Aromatic } \\
\text { sorbates }\end{array}$ \\
\cline { 2 - 7 } & Hexane & Heptane & Octane & Hex-1-ene & Hept-1-ene & Benzene \\
\cline { 2 - 7 } & $\mathrm{C}_{6} \mathrm{H}_{14}$ & $\mathrm{C}_{7} \mathrm{H}_{16}$ & $\mathrm{C}_{8} \mathrm{H}_{18}$ & $\mathrm{C}_{6} \mathrm{H}_{12}$ & $\mathrm{C}_{7} \mathrm{H}_{14}$ & $\mathrm{C}_{6} \mathrm{H}_{6}$ \\
\hline $\begin{array}{c}\text { Density (in } 298 \mathrm{~K}) \\
{\left[\mathrm{g} / \mathrm{cm}^{3}\right]}\end{array}$ & 0.659 & 0.675 & 0.703 & 0.678 & 0.697 & 0.874 \\
\hline Dipole moment $[\mathrm{D}]$ & 0.05 & 0.00 & 0.00 & 0.40 & 0.34 & 0.00 \\
\hline Radius of rotation $[\AA \hat{\mathrm{A}}]$ & 3.812 & 4.267 & 4.680 & 3.647 & 4.097 & 5.850 \\
\hline \multicolumn{7}{|c|}{ Critical parameters } \\
\hline$T_{c}[\mathrm{~K}]$ & 507.68 & 540.17 & 568.84 & 504.03 & 537.29 & 561.95 \\
\hline$p_{c}[\mathrm{MPa}]$ & 3.040 & 2.736 & 2.488 & 3.140 & 2.920 & 4.740 \\
\hline$d_{c}\left[\mathrm{~g} / \mathrm{cm}^{3}\right]$ & 0.2351 & 0.2352 & 0.2322 & 0.2377 & 0.2400 & 0.0309 \\
\hline
\end{tabular}

Testing was done on a hard coal sample from a Polish colliery (KWK Pniówek), designated as coal P. The parameters of the test coal were determined by the technical, elemental (Tab. 2), petrographic (Tab. 3). Porosity and densitometric methods and its helium density were established accordingly (Tab. 4).

Table 2

Chemical and technological analysis of the coal studied

\begin{tabular}{|c|c|}
\hline Parameter & Mass percentage [wt. \%] \\
\hline C & 84.24 \\
\hline S (total) & 0.39 \\
\hline S (pyritic) & 0.01 \\
\hline H & 4.58 \\
\hline N & 1.52 \\
\hline S (ash) & 0.07 \\
\hline S (flameable) & 0.32 \\
\hline O & 4.58 \\
\hline Moisture $\mathrm{W}^{\mathrm{a}}$ & 1.75 \\
\hline Ash $\mathrm{A}^{\mathrm{a}}$ & 3.01 \\
\hline Volatile matter $^{\mathrm{a}}$ & 27.12 \\
\hline
\end{tabular}


Table 3

Petrographic analysis of the coal studied

\begin{tabular}{|c|c|c|c|c|c|}
\hline \multirow{2}{*}{ Sample } & \multicolumn{5}{|c|}{ Group of macerals [\%] } \\
\cline { 2 - 6 } & vitrinite & liptinite & inertinite & mineral matter & reflektivity \\
\hline $\mathrm{P}$ & 73 & 7 & 20 & 1 & 0.92 \\
\hline
\end{tabular}

Table 4

Results of prorosity investigation: total volume of pores and porosity

\begin{tabular}{|c|c|c|c|c|c|c|}
\hline \multirow{3}{*}{ Sample } & \multicolumn{2}{|c|}{ Range $(5-58,000 \mathrm{~nm})$} & \multicolumn{2}{c|}{ Range $(5-7,500 \mathrm{~nm})$} & \multicolumn{2}{c|}{ Range $(7,500-58,000 \mathrm{~nm})$} \\
\cline { 2 - 7 } & $\begin{array}{c}\text { volume of } \\
\text { pores } \\
{\left[\mathrm{mm}^{3} / \mathrm{g}\right]}\end{array}$ & $\begin{array}{c}\text { porosity } \\
{[\%]}\end{array}$ & $\begin{array}{c}\text { volume of } \\
\text { pores } \\
{\left[\mathrm{mm}^{3} / \mathrm{g}\right]}\end{array}$ & $\begin{array}{c}\text { porosity } \\
{[\%]}\end{array}$ & $\begin{array}{c}\text { volume of } \\
\text { pores } \\
{\left[\mathrm{mm}^{3} / \mathrm{g}\right]}\end{array}$ & $\begin{array}{c}\text { porosity } \\
{[\%]}\end{array}$ \\
\hline $\mathrm{P}$ & 25.32 & 3.24 & 21.80 & 2.81 & 3.42 & 0.44 \\
\hline
\end{tabular}

On account of the complex physico-chemical nature of hard coal, the reported interpretations of its sorption properties with respect to low-molecular substances are mostly qualitative. Because of the low sorption capacity and the long time required for the sorption equilibrium to establish, the optimal time required to obtain one measurement point would be two or three days.

\section{RESULTS AND DISCUSSION}

In the tri-dimensional structure of hard coals there are free spaces of a closed or open structure, of variable size and shape, creating a very heterogeneous capillary structure. These free spaces are responsible for the general porosity of coals, consisting of various systems: submicro-, micro-, meso-, and macro-pores, up to fissures and crackings of micron dimensions. The content of submicro and micro-pores determines the value of specific surface area, while their volume depends upon the quantitative contribution of the largest macropores in the capillary structure of coal. Usually the contribution of mesopores is small, both in specific surface area and in total volume of pores. Nevertheless, meso- and macropores are the sites of mono- and poly-molecular adsorption and therefore the adsorption capacity of coal is determined by surface area of these pores (Krzyżanowski \& Żyła 2007). The maximal sorption capacity of investigated coal samples was found to decrease with the increased length of the sorbate chain, which is caused by a larger kinetic diameter of sorbate molecules in relation to the diameter of pores dominant in the pore structure (Fig. 1). Probably, adsorbed alkane molecules block the access to the next pores, and this effect is more pronounced for longer hydrocarbon chains. According to literature reports (Żyła et al. 1991), this is indicative of formation of discoidal and globular groups on the surface, and of incomplete penetration of the porous structure of coal by hydrocarbon chains. In the case of higher rank coals, the chains of sorbed molecules will be arranged along the geometric surface of coal, blocking 
the access to its internal structure. Apart from the geometric factors, associative (sorbatesorbate) interactions between the sorbate molecules in the absorbed phase will play some role, too (Nodzeński et al. 2003, Orzechowska-Zięba \& Nodzeński 2008).

According to the research data, sorption of vapours of non-polar substances involves mostly the surface process and it is dependent on porosity of hard coals, particularly on the micro- and mesopore development. Comparison of the sorption capacities suggests that the porous structure of the investigated coal exhibits the properties of a molecular sieve.

In the processes of sorption of non-saturated hydrocarbons (Figs 2, 3) of particular importance is the presence of pi-electrons in the aromatic coalpolymer, which interact with pielectrons in non-saturated hydrocarbons molecules. These interactions lead to higher values of sorption capacity of alkanes with respect to alkenes with the similar chain length.

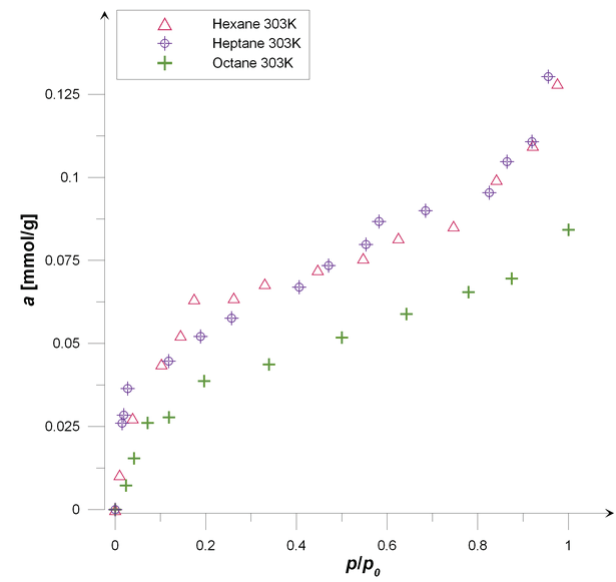

Fig. 1. Isotherm for hexane, heptane and octane sorption for P sample

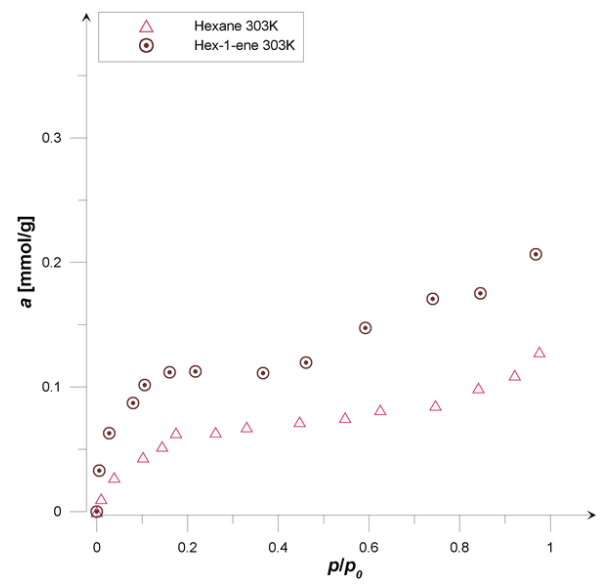

Fig. 2. Isotherm for hexane and hex-1-ene sorption for P sample 


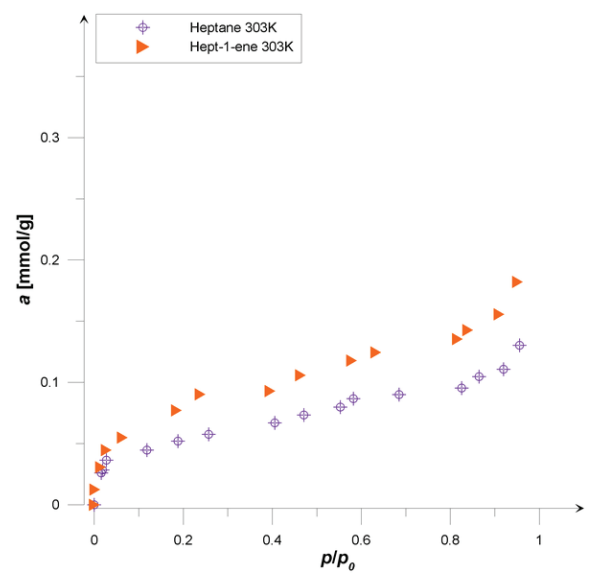

Fig 3. Isotherm for heptane and hept-1-ene sorption for P sample

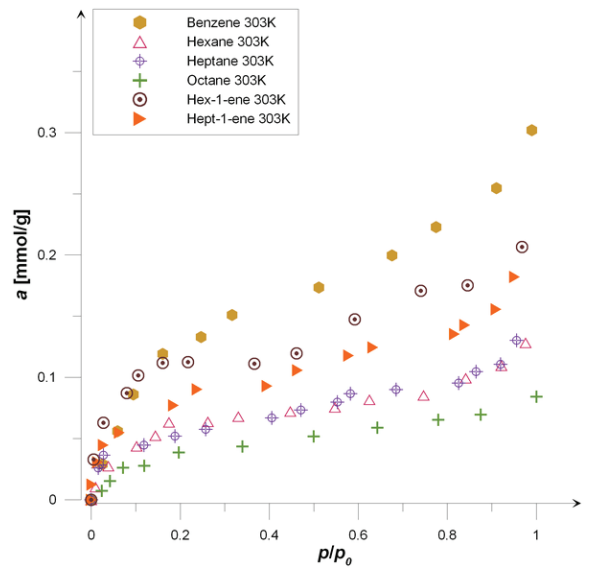

Fig. 4. Isotherm for vapours of hexane, hex-1-ene, heptane, hept-1-ene, octane and benzene for P sample

Unlike other long-chained hydrocarbons, hexane is able to penetrate deep inside the micropores and the presence of a dual bond in the hex-1-ene molecule hinders the penetration of non-saturated hydrocarbon into the porous structure of coal. Low levels of sorption capacity with respect to saturated hydrocarbons may be attributable to the oxygen groups' screening of the coal's polar bulk with respect to polar molecules of the sorbate.

A number of the coal surface properties (especially sorption property) due to the presence of hydrophilic groups formed from oxygen and nitrogen atoms. Changing the reactivity of these groups is reflected in sorption processes. Higher sorption values registered for benzene vapours in relation to the remaining saturated/non-saturated sorbates are mostly due to the polarity of a benzene molecule (Krzyżanowski \& Żyła 2007), associated with pi-electrons movements within the benzene molecule (Fig. 4). 
Benzene molecules in relation to coal surface exhibit characteristics of polar sorbate. This can be explained by the presence in the molecule of benzene $\pi$ electrons, which give it a dipole moment. This is reflected in the interaction of benzene molecules with polar centers of the coal surface. In the case of this sorbate, relatively large amounts are sorbed in the low range of relative pressures; in excess of $p / p_{0}=0.15$ the sorption process becomes stabilised. This isotherm pattern is characteristic of sorption taking place mostly in micropores.

\section{CONCLUSIONS}

The presence of a dual bond in the hydrocarbon molecule affects the isotherm pattern and leads to the higher sorption values. The favoured sorption of polar hydrocarbons may be associated with the interactions of the dual bond with functional polar groups on the coal surface. Since the saturated and non-saturated hydrocarbon molecule dimensions are very similar, the differences in sorption capacity are probably the result of associations of non-saturated hydrocarbon molecules on the surface of micropores. It is reasonable to suppose that in the case of non-saturated hydrocarbons adsorbate-adsorbate interactions play a more significant role than adsorbate-adsorbent processes. Sorption capacity for vapours of apolar substances is relatively low, which may be attributable to the mechanism of their adsorption by hard coal whilst the porous structure of hard coal used in the experiments behaves as a molecular sieve. It can be assumed that in the investigated systems sorption takes place mostly on the surface of macropores in hard coal. Results of conducted tests offer us a better insight into the factors controlling the processes of gas sorption and gas release in the hard coal-vapour/gas systems, hence they can be well utilised in prognosticating the gas release to mine workings during the mining operations, rock bursts, rock and gas outbursts and particularly during the self-heating of coal.

The work has been carried out of the AGH project no. 11.11.210.244.

\section{REFERENCES}

Bradley R.H. \& Rand B., 1995. O the physical adsorption of vapors by microporous. Carbons. Journal of Colloid and Interface Science, 169, 1, 168-176.

Chen Z., Liu J., Elsworth D., Connell L.D. \& Pan Z., 2010. Impact of $\mathrm{CO}_{2}$ injection and differential deformation on $\mathrm{CO}_{2}$ injectivity under in-situ stress conditions. International Journal of Coal Geology, 81, 97-108.

Clarkson C.R. \& Bustin R.M., 1999. The effect of pore structure and gas pressure upon the transport properties of coal: a laboratory and modelling study: 1. Isotherms and pore volume distributions. Fuel, 78, 1333-1344.

Huang Z.H., Kang F., Zheng Y.P., Yang J.B. \& Liang K.M., 2002. Adsorption of trace polar methy-ethyl-ketone and non-polar benzene vapors on viscose rayon-based activated carbon fibers. Carbon, 40, 8, 1363-1367. 
Kotarba M., 2001. Composition and origin of coalbed gases in the Upper Silesian and Lublin basins, Poland. Organic Geochemistry, 32, 163-180.

Krzyżanowski A. \& Żyła M., 2007. Characteristics of water, methanol and benzene vapours sorption properties of selected metamorphic types of hard coal. Gospodarka Surowcami Mineralnymi - Mineral Resources Management, 23, 4, 139-147.

Labus K., Tarkowski R. \& Wdowin M., 2010. Assessment of $\mathrm{CO}_{2}$ sequestration capacity based on hydrogeochemical model of water-rock-gas interactions in the potential storage site within the Bełchatów area (Poland). Gospodarka Surowcami Mineralnymi - Mineral Resources Management, 26, 2, 71-84.

Mirasol J.R., Bedia J., Cordero T. \& Rodríguez J.J., 2005. Influence of water vapor on the adsorption of VOCs on lignin-based activated carbons. Separation Science and Technology, 40, 3113-3135.

Nodzeński A., Hołda S. \& Orzechowska-Zięba A., 2003. Adsorbate-adsorbate interactions in a hard coal - heptane, heptene-1 system. Annals of the Polish Chemical Society, 2, $1140-1143$.

Orzechowska-Zięba A. \& Nodzeński A., 2008. Chłonność sorpcyjna węgla kamiennego względem węglowodorów $\mathrm{C}_{6}-\mathrm{C}_{8}$. Gospodarka Surowcami Mineralnymi-Mineral Resources Management, 24, 3/3, 245-254.

Prusty B.K., 2007. Sorption of methane and $\mathrm{CO}_{2}$ for enhanced coalbed methane recovery and carbon dioxide sequestration. Journal of Natural Gas Chemistry, 17, 29-38.

Saha S., Sharma B.K., Kumar S., Sahu G., Badhe Y.P., Tambe S.S. \& Kulkarni B.D., 2007. Density measurements of coal samples by different probe gases and their interrelation. Fuel, 86, 1594-1600.

Shi J.Q. \& Durucan S., 2003. A bidisperse pore diffusion model for methane displacement desorption in coal by $\mathrm{CO}_{2}$ injection. Fuel, 82, 1219-1229.

Sobczyk J., 2011. The influence of sorption processes on gas stresses leading to the coal and gas outburst in the laboratory conditions. Fuel, 90, 1018-1023.

Vuthaluru H.B., Brookeb R.J., Zhanga D.K. \& Yana H.M., 2003. Effects of moisture and coal blending on Hardgrove Grindability Index of Western Australian coal. Fuel Processing Technology, 81, 1, 67-76.

Walker P.L., Verma S.K., Rivera-Ultrilla J. \& Davis A., 1988. Densities, Porosities and surface areas of coal maurals as measured by their interaction with gases. Vapours and Liquids. Fuel, 67, 1615-621.

Youssef A.M., 1974. Moisture sorption in relation to some characteristics of coal. Carbon, $12,4,433-438$.

Żyła M. \& Kreiner K., 2006. Binarny charakter powierzchni węgla kamiennego. Górnictwo i Geoinżynieria, 30, 2, 19-34.

Żyła M., Kreiner K. \& Bodek E., 1991. The problem of the chemical nature of hard coals surface and consideration gives to their sorptive properties. Archives of Mining Sciences, $36,3,263-274$. 